DOI: $10.12731 / 2070-7568-2018-1-22-37$

УДК 11.15.45

\title{
РЕФОРМА МЕСТНОГО САМОУПРАВЛЕНИЯ И ПОЛИТИКА ДЕЛЕГИРОВАНИЯ ПОЛНОМОЧИЙ МУНИЦИПАЛЬНЫМ ОБРАЗОВАНИЯМ РОССИЙСКОЙ ФЕДЕРАЦИИ: ТЕОРИЯ И ПРАКТИКА
}

\author{
Бейдина Т.Е., Кухарский А.Н., Новикова А.В.
}

Предметом исследования в данной статье является обобщение теории и практики по передаче полномочий на муниципальные уровни, в том числе по средствам самообложения граждан, инновачионному обеспечению муниципальных проектов, расширению объёма межбюджетных трансфертов и концессионных соглашений. Делегирование полномочий между ее различными уровнями являются инновационными, но существует их политико-правовое разнообразие, зависимость от федерального бюджета, огромное их неисполнение. Объем передаваемых полномочий - это процесс постоянного поиска новых форм взаимодействия и управления.

Научная новизна состоит в разработке модели эффективного распределения/перераспределения государственных полномочий между региональным и муниципальным уровнем управления в иелях модернизации системы государственного и муниципального управления РФ с учетом региональной специфики субъекта Федеращии - Забайкальского края.

Цель - провести анализ целостных систем делегирования полномочий, выделить группы государственных полномочий, передаваемых органам местного самоуправления.

Методы или методология проведения работы: прогнозный метод, планирование и прогнозирование, сравнительный метод по мониторингу передачи полномочий, метод ранжсрования, инновационные методы развития муниципального образования (развитие внутригородских кооперативных связей, аутсорсинга, активиза- 
цุия инвестирования), системный метод (обновление муниципалитетов).

Результаты: разработать модель эффективного распределения государственньх полномочий, охарактеризовать элементы модели, повысить профессиональный уровень мунищипальных управляющих, уделять особое внимание информатизаџии системь муниципального управления.

Область применения результатов: ичелесообразно применять в государственной и муниципальной политике.

Ключевые слова: местное самоуправление; политика; делегирование полномочий; Россия; Забайкальский край.

\section{LOCAL GOVERNMENT REFORM \\ AND THE POLICY OF DELEGATION OF AUTHORITY TO MUNICIPALITIES OF THE RUSSIAN FEDERATION: THEORY AND PRACTICE}

Beydina T.E., Kukharsky A.N., Novikova A.V.

The subject of the research in this article is the generalization of the theory and practice on the transfer of powers to municipal levels, including the means of self-taxation of citizens, innovative support for municipal projects, the expansion of inter-budgetary transfers and concession agreements. Delegation of powers between its various levels is innovative, but there is their political and legal diversity, dependence on the Federal budget, and huge non-compliance. The scope of authority transferred is the process of constantly seeking new forms of interaction and management.

The scientific novelty consists in the development of the model of effective distribution/redistribution of state powers between the regional and municipal levels of management in order to modernize the system of state and municipal management of the Russian Federation, taking into account the regional specifics of the subject of the FederationTRANS-Baikal territory. 
The purpose is to analyze the holistic systems of delegation of powers, to identify groups of state powers transferred to local governments.

Methods or methodology of work: forecast method, planning and forecasting, comparative method for monitoring the transfer of authority, ranking method, innovative methods of development of the municipality (development of intra-city cooperative relations, outsourcing, investment activation), system method (renewal of municipalities).

Results: to develop a model of effective distribution of state powers, to characterize the elements of the model, to improve the professional level of municipal managers, to pay special attention to the Informatization of the municipal management system.

Scope of application of the results: it is advisable to apply in state and municipal policy.

Keywords: local self-government; politics; delegation of powers; Russia; TRANS-Baikal territory.

Проблема делегирования полномочий была связана с теорией разделения властей с влиянием с Ш. Монтескье, отразившимся в его трактате «О духе законов» [13]. Принцип разделения властей признавался английской судебной практикой как один из основополагающих: «Разделение между судебной, законодательной и исполнительной ветвями государственной власти является твердым принципом нашей системы правления» [14]. В правовом поле Великобритании, как отмечал Д. Элдер: «принцип разделения властей применяется наиболее жестко, так как ее независимость является неотъемлемой чертой верховенства права» [11]. В различных государствах существуют разные подходы к проблеме разделения властей [11]. Проблема делегирования полномочий с точки зрения разделения властей применительно к Великобритании означает передачу Шотландии от метрополии необходимых функций [12]. С позиции управленческой науки проблема внедрения состоит в принципах делегирования, который предполагает единоначалие, соответствие задач характеру полномочий сотрудника, координацию, достаточность и мотивированность. Данные управленческие 
принципы были реализованы в государственном и муниципальном управлении России. В середине 2000-х гг. была проведена реформа местного самоуправления (МСУ), создана двухуровневая система МСУ и распределены полномочия между уровнями власти в Российской Федерации. Первый уровень власти - городские округа и муниципальные районы, второй - городские и сельские поселения внутри муниципальных районов. По утверждению Н. Зубаревич: «В середине 2010-х начался пересмотр реформы. Регионы не мытьем так катаньем пытаются укрупнить поселения или вернуться к одноуровневому МСУ. Некоторые регионы (Сахалинская, Свердловская обл.) сопротивлялись реформе, разделив свою территорию на городские округа, в которых не предусмотрен поселенческий уровень» [6]. Вопрос о делегировании полномочий в практике государственного и муниципального управления предусматривает наличие регламентов, правил и параметров работы государственного и муниципального управленца [9].

Аналогичным образом решен вопрос о возможности передачи полномочий органов местного самоуправления муниципального района органам местного самоуправления отдельных поселений, входящих в его состав. В ст. 173 Бюджетного кодекса РФ дополнительно предусмотрено, что прогноз социально-экономического развития поселения может разрабатываться местной администрацией муниципального района в соответствии с соглашением между местной администрацией поселения и местной администрацией муниципального района [8]. Важно обратить внимание, что речь идет только о полномочиях по решению вопросов местного значения. В практике деятельности органов местного самоуправления, безусловно, есть примеры, иллюстрирующие попытку органов местного самоуправления передавать полномочия по решению вопросов государственного значения. Но этот процесс регулируется иными нормами. Например, арбитражный суд, рассматривая конкретное дело, фактически решал вопрос о том, может ли муниципальный район передавать поселению свои полномочия, если речь идет об отдельных государственно-властных полномочиях, переданных ра- 
нее этому муниципальному району. В постановлении федерального арбитражного суда Поволжского округа от 21 декабря 2006 г. по делу № A12-14663/2006 было отмечено, что муниципальные районы, наделенные № 131-Ф3 отдельным государственным полномочием по распоряжению земельными участками, государственная собственность на которые не разграничена, не могут передавать данное полномочие органам местного самоуправления городских и сельских поселений.

Довольно большие проблемы для перераспределения полномочий создают формулировки вопросов местного значения, их сходство. Например, к вопросам местного значения поселений относится создание условий для развития местного традиционного народного художественного творчества, участие в сохранении, возрождении и развитии народных художественных промыслов в поселении (п. 13.1 ч. 1 ст. 14 № 131-Ф3); к вопросам местного значения муниципального района относится создание условий для развития местного традиционного народного художественного творчества в поселениях, входящих в состав муниципального района (п. 19.2 ч. 1 ст. 14 № 131-Ф3). Как в этом случае четко разграничить, какие полномочия должны осуществляться органами местного самоуправления района, а какие- поселениями?

Большинство формулировок вопросов местного значения начинаются со слов «создание условий», «организация», «участие в». Муниципалы не всегда четко и однозначно понимают, что на практике означают эти термины, как их «перевести в плоскость» полномочий. По мнению Минфина РФ, вопросом местного значения является именно организация предоставления бюджетных услуг или само предоставление этих услуг. Таким образом, органы местного самоуправления несут ответственность не за финансирование тех или иных муниципальных учреждений, а за весь комплекс мероприятий, имеющий конечной целью предоставление бюджетных услуг и результаты предоставления бюджетных услуг. Соответственно, мерой эффективности деятельности органов местного самоуправления является качество предоставленных бюджетных услуг, а не 
своевременность и объемы бюджетного финансирования. По соглашению поселение передает району вопрос местного значения по физкультуре. Район планирует и осуществляет: проведение районных мероприятий (за счет средств поселений, включая оплату поселением участия спортсменов на соревнования), содержание органа управления района, выезд спортсменов на соревнования регионального, федерального уровня, содержание спортивной школы, около 98\% обучаемых в которой - жители райцентра. Содержание спортивных сооружений и их строительства в поселении не планируется. Аналогичная картина складывается и по культуре. Только там еще стоит вопрос об оплате коммунальных услуг и содержания клубов по договорам, заключаемым от имени поселения органами местного самоуправления района [10].

Другой неурегулированный вопрос связан с объемом передаваемых полномочий. В федеральном законе говорится о части полномочий, однако, что понимается под термином «часть»- не уточняется. В качестве примеров можно отметить то, что некоторые поселения Калужской области передают району 24 полномочия. Получается, что в таких поселениях у органов местного самоуправления практически полностью отсутствуют полномочия по решению вопросов местного значения (полномочия передаются на уровень района). Объем работы у муниципальных служащих существенно сокращается, а заработная плата не меняется (да и ликвидировать эти органы местного самоуправления нельзя). Такая практика приводит к росту иждивенческих настроений в поселениях, выстраиванию фактически одноуровневой модели местного самоуправления. Население вводится в заблуждение относительно того, кто должен предоставлять муниципальные услуги.

Что касается проблемы разграничения полномочий, то начнем с базовых дефектов. Во-первых, критерии выделения поселений были заданы сверху и не учитывали огромных региональных различий в расселении. Минимально необходимая численность населения в сельском поселении часто противоречила критерию территориальной доступности центра поселения для жителей других сел. 
За основу обычно бралась численность, поэтому территориальная доступность низовых органов МСУ для сельских жителей ухудшилась. Во-вторых, подавляющее большинство сельских поселений, за исключением пригородных зон агломераций, имеют мизерную налогооблагаемую базу, доходы их бюджетов минимальны. Полномочия поселений подгонялись под низкую налоговую базу и они минимальны: благоустройство и вывоз мусора, содержание учреждений культуры и внутрипоселенческих дорог. Даже при минимуме полномочий доля трансфертов из вышестоящих бюджетов в 2016 г. в сельских поселениях достигала 59\%, в городских $-41 \%$. Дистрофия финансов поселений очевидна: доходы бюджетов всех городских поселений - 154,6 млрд руб., а доходы муниципальных районов - 1467,8 млрд руб., хотя и они в основном живут за счет трансфертов (74\% в 2016 г.). В-третьих, многие города, даже относительно крупные, получили статус городских поселений, сократились их полномочия и финансовые ресурсы. Часть городских поселений смогла позднее добиться статуса городских округов, за 2011-2016 гг. их стало больше на 9\% (рост с 515 до 563). Количество городских поселений сократилось за тот же период на $8 \%$, но их все еще много (1592) [7].

Фактически реформа проводилась для более четкого разграничения полномочий, а не для передачи их вниз, ближе к населению. Ничего не было сделано и для стимулирования локальной самоорганизации, особенно в городах, а в постаревшей сельской местности с ее низким человеческим капиталом это сделать еще труднее. Нужно сохранить для будущего, спящий пока институт местного самоуправления низового уровня. Он существовал и в царской России (волости), даже в советское время был его плохонький аналог - сельсоветы. Низовой уровень необходим с учетом больших расстояний и плохой инфраструктуры в России. Жители взаимодействуют именно с низовыми органами самоуправления, которые нужно сохранять как площадку для контактов власти и населения.

Политика в отношении городских поселений иная. Города с населением свыше 50000 человек (граница условная) должны ав- 
томатически получать статус городского округа, чтобы их власти могли отстаивать интересы развития города, не подчиняясь властям муниципального района. Придется учиться договариваться по горизонтали, хотя в России это большая проблема. Возможны конфликты и ухудшение связей города с окружающей сельской территорией, которой управляют власти муниципального района, но развитие городов более приоритетно. Для городов с населением более 50000 жителей есть смысл провести референдум: стать городским округом или остаться городским поселением. Если жители не готовы бороться за повышение статуса, не нужно форсировать ситуацию.

Полноценного низового самоуправления не возникнет до тех пор, пока у него не будет налоговой базы. Для села это очень долгая перспектива, особых надежд нет. Начинать нужно с городских округов, которые имеют более значительную налоговую базу, хотя ее подрывает изъятие НДФЛ в региональный бюджет. По утверждению И. Зубаревич: «Конкурентные преимущества крупных городов - основа развития страны, но их невозможно реализовать при тотальном изъятии налоговых доходов» [6].

Передача полномочий на уровень городских поселений может реализоваться как инновационный проект. С учетом общегосударственного значения отдельных вопросов, требующих комплексных и взаимосогласованных действий органов всех уровней власти, в указанный перечень целесообразно также включить отдельные вопросы местного значения:

- участие в профилактике терроризма и экстремизма;

- участие в предупреждении и ликвидации последствий чрезвычайных ситуаций в границах поселения.

Ряд полномочий с учетом местных особенностей более эффективно может быть решен на поселковом уровне:

- обеспечение мер пожарной безопасности в границах поселения;

- организация библиотечного обслуживания населения;

- сохранение, использование и популяризация объектов культурного наследия; 
- создание условий для развития местного традиционного народного художественного творчества;

- организация обустройства мест массового отдыха населения;

- формирование архивных фондов поселения;

- организация освещения улиц;

- содержание мест захоронения;

- содействие в развитии сельскохозяйственного производства, создание условий для развития малого и среднего предпринимательства;

- организация и осуществление мероприятий по работе с детьми;

- создание условий по охране общественного порядка.

Для решений вопросов местного значения важны концессионные соглашения, представляющие собой сотрудничество инвестора (концессионера), реконструирующего или создающего имущество, право собственности на которое будет принадлежать (принадлежит) концеденту (орган исполнительной власти федерального, регионального, местного уровня власти). Как показало ранее произведенное исследование, среди предусмотренных законом возможных объектов концессионных соглашений в Забайкальском крае таковыми становятся инфраструктура по обеспечению тепло, водоснабжения и водоотведения [5].

В 281-Ф3 отмечено «Органы местного самоуправления имеют право дополнительно использовать собственные материальные ресурсы и финансовые средства в случаях и порядке, предусмотренных решением представительного органа муниципального образования» [1]. Спустя еще один год все три первые абзаца ч. 4 ст. 15 претерпели изменения [2], связанные с заменой категории «субвенции» на категорию «межбюджетные трансферты», и с добавлением ссылки на Бюджетный кодекс РФ, то есть была более четко прописана бюджетная составляющая института передачи полномочий.

Передача полномочий сельскому поселению допускается на взаимной основе, в любом направлении - как от поселения району, так и от района поселению. Отдельно говорится о возможности передачи на уровень муниципальных районов полномочий 
органов местного самоуправления поселений по регулированию тарифов на товары и услуги организаций коммунального комплекса (за исключением тарифов на товары и услуги организаций коммунального комплекса - производителей товаров и услуг в сфере электро- и (или) теплоснабжения), тарифов на подключение к системе коммунальной инфраструктуры, тарифов организаций коммунального комплекса на подключение, надбавок к тарифам на товары и услуги организаций коммунального комплекса, надбавок к ценам, тарифам для потребителей (п. 4.1 ч. 1 ст. 17 Ф3 «Об общих принципах организации местного самоуправления в Российской Федерации»; полномочий местной администрации поселения по формированию, исполнению и (или) контролю за исполнением бюджета поселения (ч. 3 ст. 52). В ст. 173 Бюджетного кодекса РФ дополнительно предусмотрено, что прогноз социально-экономического развития сельского поселения может разрабатываться местной администрацией муниципального района в соответствии с соглашением между местной администрацией поселения и местной администрацией муниципального района.

Таким образом, передача полномочий сельскому поселению - это процесс постоянного поиска новых форм взаимодействия и форм управления. Инновационность данного процесса заключается в том, что сельское поселение берет столько полномочий, сколько сможет выполнить, муниципальный район определяет - сколько и какие полномочия может отдать сельскому поселению.

Проблема делегирования полномочий и её решение индивидуальна для каждой организации. Руководитель должен научиться передавать часть полномочий своим сотрудникам для наиболее эффективного результата, ведь освободившись от рутинной работы у него появится больше времени для выполнения более важной. Руководитель должен контролировать весь процесс работы сотрудника и передача части своих функций должна быть осуществлена в соответствии с законодательством РФ. В статье 151 Трудового кодекса РФ четко говорится: «Работнику, выполняющему у одного и того же работодателя наряду со своей основной работой, обуслов- 
ленной трудовым договором, дополнительную работу по другой профессии (должности) или исполняющему обязанности временно отсутствующего работника без освобождения от своей основной работы, производится доплата за совмещение профессий (должностей) или исполнение обязанностей временно отсутствующего работника. Размеры доплат за совмещение профессий (должностей) или исполнение обязанностей временно отсутствующего работника устанавливаются по соглашению сторон трудового договора» [3]. Это касается, прежде всего, муниципальных образований. Но, безусловно, затрагивает и продуктивную работу государственного аппарата региона. Как было отмечено А.В. Новиковой и Т.Е. Бейдиной: «Обновление структуры исполнительных органов власти Забайкальского края можно охарактеризовать с положительной стороны» [4]. Данная модернизация будет способствовать эффективному решению социально-экономических проблем депрессивного Забайкальского края.

\section{Выводы}

Делегирование полномочий предполагает финансовое обеспечение, в том числе часто передаваемых полномочий муниципалитетов: по содержанию мест захоронения, по вывозу мусора, по поддержанию жилищного фонда муниципалитета, по организации массового отдыха, энергоснабжению населения.

Для осуществления делегирования полномочий муниципальным образованиям целесообразно использовать не только местные бюджеты, но и собираемые собственные средства самообложения жителей - разовые платежи, равные для всех жителей муниципалитета. Необходимо создавать резервы развития, в том числе фонды региональных средств самообложения жителей, эффективно управлять собственностью, расширять налоговую базу по местным сборам.

Более эффективно привлекать инвестиции по муниципальным проектам, поддерживать малый бизнес на территориях, расширять концессионные соглашения по строительству платных автомобиль- 
ных дорог, совместному использованию муниципальных заводов, увеличивать объем межбюджетных трансфертов и поддержку местных инициатив.

Развивать формы межмуниципального сотрудничества: ассоциативные, договорные и организационно-хозяйственные.

Повышение квалификации муниципальных служащих путем проведения выездных семинаров.

\section{Список литературы}

1. Федеральный закон от 25.12.2008 N 281-Ф3 «О внесении изменений в отдельные законодательные акты Российской Федерации» // Российская газета. 2008. 29 декабря.

2. Федеральный закон от 28.11.2009 N 283-Ф3 «О внесении изменений в отдельные законодательные акты Российской Федерации» // Российская газета. 2009. 30 ноября.

3. Трудовой кодекс Российской Федерации от 30.12.2001 N 197-Ф3 (ред. от 31.12.2017) ТК РФ Статья 151. [Электронный ресурс]. http:// www.consultant.ru/document/cons_doc_LAW_34683/2776d76376c800 a4693157045be7f028798f5046/ (дата обращения 15.02.18).

4. Бейдина Т.Е. Новикова А.В. Модернизация регионального управления Забайкальского края по назначению губернатора Н.Н. Ждановой // Вестн. Забайкал. гос. ун-та. 2017. Т.23. №1. С. 71.

5. Галынис К.И. Концессионные соглашения как инструмент муниципально-частного партнерства // Вестник Забайкальского государственного университета. 2017. Т. 23. № 8. С. 132-143.

6. Зубаревич Н. О дефектах реформы и вреде фискальных приоритетов [Электронный ресурс]. https:/www.vedomosti.ru/opinion/articles/2017/06/28/699631-chto (дата обращения 03.02.18).

7. Карчевская С. Вопросы, связанные с реализацией межмуниципальных соглашений по передаче части отдельных полномочий между муниципальным районом и поселениями [Электронный ресурс]. http://bujet.ru/article/54344.php (дата обращения 03.02.18).

8. Муниципальное управление / Под ред. И.В. Стародубровской. М., 2006. C. 520-521. 
9. Основы менеджмента // Под ред. проф. И.Ю. Солдатовой, Н.А. Чернышева. М.: Наука-Пресс, 2006.

10. Савранская О.Л. Проведение исследования по изучению вопросов, связанных с выбором наиболее адекватного способа осуществления органами местного самоуправления своих функций по организации предоставления услуг гражданам, в том числе меж-муниципального сотрудничества и муниципального заказа. [Электронный ресурс]. www.federalism.ru/docs/rt_09.06_sav.doc (дата обращения 14.02.18).

11. Alder J. Constitutional and administrative law. Ninth Edition. Palgrave Macmillan Law Masters. TJ International Ltd, Padstow, Cornwall, Great Britain. P. 129.

12. Bowers P. The Sewel Convention. Parliament and Constitutional Centre. Standard Note: SN/PC/2084. 25 November 2005. www.parliament.uk/ briefing-papers/ sn02084.pdf (дата обращения: 10.10.2014 г.).

13. Montesquieu C. The Spirit of the Laws (1748). Chapter 6. Of the Constitution of England. www.etext.lib.virginia.edu/etcbin/to...public\&part=137\&division=div2 (дата обращения: 10.02.18).

14. R (Anderson) v Secretary of State for the Home Department [2002] UKHL 46 [2003] 1 AC 837 at [39] // Fordham M. Judicial Review Handbook. Fifth Edition. Hart Publishing Ltd. Oxford - Portland Oregon, 2008. P. 71.

\section{References}

1. Federal'nyy zakon ot 25.12.2008 N 281-FZ «O vnesenii izmeneniy v otdel'nye zakonodatel'nye akty Rossiyskoy Federatsii» [Federal Law No. 281-FZ of 25.12.2008 "On Amending Certain Legislative Acts of the Russian Federation"]. Rossiyskaya gazeta. December 29, 2008.

2. Federal'nyy zakon ot 28.11.2009 N 283-FZ «O vnesenii izmeneniy v otdel'nye zakonodatel'nye akty Rossiyskoy Federatsii» [Federal Law of 28.11.2009 N 283-FZ "On Amending Certain Legislative Acts of the Russian Federation”]. Rossiyskaya gazeta. November 30, 2009.

3. Trudovoy kodeks Rossiyskoy Federatsii ot 30.12.2001 N 197-FZ (red. ot 31.12.2017) TK RF Stat'ya 151 [The Labor Code of the Russian Federation of December 30, 2001 No. 197-FZ (as amended on December 31, 
2017) of the RF TC Article 151]. http://www.consultant.ru/document/ cons_doc_LAW 34683/2776d76376c800a4693157045be7f028798f5046/

4. Beydina T.E., Novikova A.V. Vestn. Zabaykal. gos. un-ta. 2017. V.23. №1. P. 71.

5. Galynis K.I. Vestnik Zabaykal'skogo gosudarstvennogo universiteta. 2017. V. 23. № 8, pp. 132-143.

6. Zubarevich N. O defektakh reformy $i$ vrede fiskal'nykh prioritetov [On the Defects of the Reform and the Dangers of Fiscal Priorities]. https://www. vedomosti.ru/opinion/arti-cles/2017/06/28/699631-chto (data obrashcheniya 03.02.18).

7. Karchevskaya S. Voprosy, svyazannye s realizatsiey mezhmunitsipal'nykh soglasheniy po peredache chasti otdel'nykh polnomochiy mezhdu munitsipal'-nym rayonom i poseleniyami [Issues related to the implementation of intermunicipal agreements on the transfer of certain powers between the municipal district and settlements]. http://bujet.ru/article/54344.php

8. Munitsipal'noe upravlenie [Municipal management] / ed. I.V. Starodubrovskaya. M., 2006. P. 520-521.

9. Osnovy menedzhmenta [Fundamentals of Management] / ed. prof. I.Yu. Soldatova, N.A. Chernyshev. M. Nauka-Press, 2006.

10. Savranskaya O.L. Provedenie issledovaniya po izucheniyu vopro-sov, svyazannykh s vyborom naibolee adekvatnogo sposoba osushchestvleniya organami mestnogo samoupravleniya svoikh funktsiy po organizatsii predostavleniya uslug grazhdanam, $v$ tom chisle mezhmunitsipal'nogo sotrudnichestva i munitsipal'nogo zakaza [Carrying out a study to study the issues related to the choice of the most appropriate way for local government bodies to carry out their functions in organizing the provision of services to citizens, including inter-municipal cooperation and a municipal order]. www.federalism.ru/docs/rt_09.06_sav.doc

11. Alder J. Constitutional and administrative law. Ninth Edition. Palgrave Macmillan Law Masters. TJ International Ltd, Padstow, Cornwall, Great Britain. P. 129.

12. Bowers P. The Sewel Convention. Parliament and Constitutional Centre. Standard Note: SN/PC/2084. 25 November 2005. www.parliament.uk/ briefing-papers/sn02084.pdf 
13. Montesquieu C. The Spirit of the Laws (1748). Chapter 6. Of the Consti-tution of England. www.etext.lib.virginia.edu/etcbin/to...public\&part=137\&division=div2 (data ob-rashcheniya: 10.02.18).

14. R (Anderson) v Secretary of State for the Home Department [2002] UKHL 46 [2003] 1 AC 837 at [39] // Fordham M. Judicial Review Handbook. Fifth Edition. Hart Publishing Ltd. Oxford - Portland Oregon, 2008. P. 71.

\section{ДАННЫЕ ОБ АВТОРАХ}

Бейдина Татьяна Евгеньевна, доктор политических наук, професcop, кафедра государственного, муниципального управления и политики. Забайкальский государственный университет ул. Александро-Заводская, 30, г. Чита, Забайкальский край, 672039, Российская Федерачии beydina@inbox.ru

Кухарский Артем Николаевич, магистрант кафедры государственного, муниципального управления и политики Забайкальский государственный университет ул. Александро-Заводская, 30, г. Чита, Забайкальский край, 672039, Российская Федерачия kukharskijjartjom@yandex.ru

Новикова Анна Владимировна, кандидат политических наук, доцент кафедры государственного, муниципального управления и политики

Забайкальского государственного университета ул. Александро-Заводская, 30, г. Чита, Забайкальский край, 672039, Российская Федераџия. beydina@inbox.ru

\section{DATA ABOUT THE AUTHORS}

Beydina Tatiana Evgenievna, Doctor of Political Sciences, Professor, Chair of State Municipal Management and Policy 
Zabaikalsky State University

30, Aleksandro-Zavodskaya Str., Chita, Zabaykalsky Krai, 672039, Russian Federation

beydina@inbox.ru

Kuharsky Artem Nikolaevich, Graduate Student of the Department of State, Municipal Management and Policy

Zabaikalsky State University

30, Aleksandro-Zavodskaya Str., Chita, Zabaykalsky Krai, 672039, Russian Federation

kukharskijjartjom@yandex.ru

Novikova Anna Vladimirovna, candidate of political Sciences, associate Professor, chair of public administration and politics Zabaikalsky State University

30, Aleksandro-Zavodskaya Str., Chita, Zabaykalsky Krai, 672039, Russian Federation

beydina@inbox.ru 